\title{
Mengapa Jepang Memilih Hadratussyaikh: Analisa Sejarah Ditunjuknya KH. Hasyim Asy'ari Menjadi Ketua Masyumi
}

\author{
Muhammad As'ad \\ Universitas Hasyim Asy'ari \\ muhammad.asad@tebuireng.net
}

\begin{abstract}
This article seeks to answer why the Japanese chose KH. Hasyim Asy'ari as the chairman of Masyumi during their occupation in Indonesia (1942-1945). The data was collected from library research by scrutinizing paper and academic works that discuss Indonesia from the 1920s to its independence in 1945. This period is important to understand the historical and political conditions of the country at that time. This article also refers to two magazines of Suara MIAI that began publishing in December 1942 and Suara Masyumi Magazine issued from December 1943 onward. This article argues that the Japanese decision to choose Hadratussyaikh was based on political motivation, especially to get the support of the Muslim community for Japanese efforts to fight Allied forces in the Pacific war.
\end{abstract}

Keywords: Masyumi; Japan; Hadratussyaikh; Hasyim Asy'ari

\section{Pendahuluan}

Yang kita ketahui saat ini bahwa Hadratussyaikh Hasyim Asy'ari menjadi tokoh yang dipercaya oleh penjajah Jepang untuk memimpin dua lembaga penting. Lembaga tersebut adalah Majelis Syuro Muslimin Indonesia (Masyumi) pada tahun 1943 dan Shuumubu (Kantor Urusan Agama) pada tahun 1944. Kedua lembaga ini diserahkan tampuk kepemimpinannya kepada Hadratussyaikh karena beberapa faktor yang akan saya jelaskan dalam beberapa bagian di bawah ini. 
Beberapa bagian yang saya tulis nanti penting untuk dibaca dan diketahui sebagai sebuah proses kronologis dalam sejarah kita. Dimana dalam proses tersebut pada akhirnya Hadratussyaikh tercatat tidak hanya sebagai tokoh utama dalam penulisan sejarah Islam di Indonesia, tetapi sejarah nasionalisme di negara kita.

Artikel ini akan menjawab satu pertanyaan, mengapa Hadratussyaikh dipilih oleh Jepang menjadi ketua Masyumi yang akhirnya mengantarkan beliau menjadi salah satu tokoh utama pada masa kemerdekaan? Untuk menjawab pertanyaan tersebut, penulis menggunakan data skunder dan primer. Untuk yang pertama penulis memakai buku dan penelitian ilmiah yang membahas Indonesia rentang waktu tahun 1920an hingga kemerdekaan. Rentang waktu tersebut penulis lihat untuk memahami kondisi historis dan politis pada masa tersebut. Untuk yang kedua, penulis merujuk majalah Suara MIAI yang mulai terbit pada bulan Desember 1942 dan Majalah Suara Masyumi yang mulai terbit pada Desember 1943.

Untuk struktur artikel ini, penulis akan terlebih dahulu membahas isu persatuan Islam yang selalu muncul dan hilang dalam sejarah Indonesia. Isu ini dibahas agar kita bisa mengetahui akar pokok masalah di banyak kelompok Islam di Indonesia, yang berujung pada sulitnya mempersatukan kelompok-kelompok tersebut dalam satu organisasi. Berikutnya akan membahas munculnya MIAI dan Masyumi sebagai implementasi persatuan Islam dan terakhir tentang pola penjajah Jepang dalam merangkul umat Islam untuk kepentingan mereka dalam perang pasifik melawan Sekutu.

Pada artikel ini ini, penulis berargumen bahwa keputusan Jepang memilih Hadratussyaikh karena menganggap beliau bisa dimanfaatkan untuk kepentingan politik khususnya memobilisasi masyarakat Muslim Indonesia dalam usaha Jepang melawan pasukan Sekutu di perang pasifik.

\section{Perbedaan Manhaj dan Sulitnya Persatuan Islam}

Persatuan Islam mungkin satu kalimat yang sering kita dengar saat ini, apalagi ketika musim Pemilu dimana isu ini selalu dipakai di negara kita oleh beberapa partai Islam. Pada faktanya, ide dan implementasi persatuan Islam dalam sejarah Islam di Indonesia terutama pada abad 20, adalah sesuatu yang naik-turun. Artinya ide ini pernah terlaksana, dan pernah juga antara sesama kelompok Islam saling menjatuhkan. Sulitnya persatuan Islam di Indonesia berakar pada polarisasi kelompok Islam di Indonesia yang paling tidak terbagi dalam dua kelompok besar: modernis dan tradisional. Secara kajian akademik, dua istilah ini sedikit usang, akan tetapi tetap dipakai dan relevan sampai sekarang. 
Untuk istilah pertama, Charles Adams ${ }^{1}$, seorang orientalis Amerika yang termasuk ilmuwan pertama menggunakan istilah modernisme Islam, menggambarkan modernisme sebagai upaya untuk mengubah Islam dari ortodoksi yang kaku menjadi agama yang disesuaikan dengan kehidupan modern. Ada juga yang menggunakan terma reformisme Islam untuk menjelaskan gerakan diatas. Ilmuwan Indonesia Deliar Noer, ${ }^{2}$ yang menulis buku tentang sejarah modernis Muslim di Indonesia, cenderung tidak menggunakan satu kata terkait modernisme. Noer menggunakan kedua istilah modernisme Islam dan reformisme Islam secara bergantian. Secara konseptual, modernisme Islam diartikan sebagai sebuah gerakan yang mengadopsi metode mempertahankan tafsir langsung $\mathrm{Al}$ Qur'an dan hadis, serta mempertanyakan otoritas hierarki ulama (mazhab) tradisional. Tampaknya metode ini memiliki kemiripan dengan Salafisme yang kita dengar akhir-akhir ini. Tetapi berbeda dengan Salafi, reformis percaya pada interpretasi rasional Al-Qur'an dan hadis oleh individu Muslim (ijtihad), sedangkan Salafi tidak. Metode ini sangat dipengaruhi oleh para pemikir seperti Jamaluddin al-Afghani (1839-1897), Muhammad Abduh (1849-1905) dan Rashid Ridha (1865 -1935). ${ }^{3}$ Untuk makalah ini saya menggunakan istilah modernisme karena biasa dipakai oleh kalangan sarjana di Indonesia.

Terkait tradisionalisme, istilah ini dalam kajian studi Islam sebenarnya merujuk kepada ahl-hadith, mazhab pemikiran Islam yang menganggap bahwa AlQur'an dan Hadith adalah satu-satunya sumber hukum Islam yang otentik. ${ }^{4}$ Namun di Indonesia, istilah tradisionalisme tidak seperti dalam kajian pada umumnya akan tetapi lebih merujuk kepada umat Islam yang mengikuti tradisi ulama dan taqlid kepada salah satu dari empat mazhab fikih. ${ }^{5}$

\footnotetext{
${ }^{1}$ Charles Adams, Islam and Modernism in Egypt: A Study of the Modern Reform Movement Inaugurated by Muhammad Abduh (New York: Oxford University Press, 1933), 1.

2 Deliar Noer, Modernist Muslim Movements in Indonesia (Kuala Lumpur: Oxford University Press, 1973).

3 Hisham Sharabi, Arab Intellectuals and the West: The Formative Years, 1875-1914 (Baltimore and London: Johns Hopkins University Press, 1970), 24.

${ }^{4}$ John L. Esposito, The Oxford Dictionary of Islam (Oxford University Press, 2004), 9; Marshall GS Hodgson, The Venture of Islam, Volume 1: The Classical Age of Islam (University of Chicago press, 2009), 66.

5 Martin Van Bruinessen, "Traditions for the Future: The Reconstruction of Traditionalist Discourse within NU," in Nahdlatul Ulama, Traditional Islam and Modernity in Indonesia, ed. Greg Barton and Greg Fealy (Clayton: Monash Asia Institute, 1996), 163189.
} 
Terkait perdebatan antara kelompok modernis dan tradisionalis, Di abad 20, terdapat catatan dalam sejarah beberapa perdebatan tajam antara kelompok modernis dan tradisional. Yang paling awal yang tercatat terjadi di Sumatra Barat. Mereka menamakan diri kaum muda yang adalah sekelompok Muslim yang mendukung ide modernisme Islam, dan kaum tua yang diidentikkan sebagai pembela tradisionalisme Islam. Debat terbuka antara keduanya terjadi pada tahun 1907 di Padang, Minangkabau. Kaum muda dipimpin oleh Abdullah Ahmad dan Abdul Karim Amrullah (Haji Rasul) sedangkan Kaum Tua dipimpin oleh Chatib Ali. Dalam perdebatan tersebut, isu yang paling mencuat adalah mengenai berdiri (qiyam) ditengah prosesi Maulid Nabi. ${ }^{6}$ Selain debat terbuka, saling kritik antara dua kubu ini di Padang cukup intens melalui tulisan. Paling tidak melalui majalah Al-Munir yang merupakan corong kaum muda di Padang. Dan juga jaringannya di Singapura melalui majalah Al-Imam. ${ }^{7}$ Debat terbuka berikutnya yang tercatat

\footnotetext{
${ }^{6}$ Nico Kaptein, "The Berdiri Mawlid Issue among Indonesian Muslims in the Period from circa 1875 to 1930," Bijdragen Tot de Taal, Land- En Volkenkunde 149, no. 1 (1993): 135.

${ }^{7}$ Dua majalah ini merupakan jaringan dari murid dan kolega Rashid Rida melalui majalah Al-Manar. Dari segi sampul, nama dan konten ketiga majalan ini mirip. Secara umum, berbagai macam kritik terhadap tradisi agama kaum tradisional oleh kelompok modernis imbas dari jaringan ulama yang pulang dari belajar timur tengah dan kembali ke Indonesia untuk berdakwah. Dari karya beberapa peneliti (William Roff, Azyumardi Azra, Jajat Burhanuddin, dan Hafiz Zakariya), salah satu orang yang paling awal menyebarkan gagasan reformisme Islam di Asia Tenggara maupun di Indonesia adalah Tahir Jalaluddin (1869 - 1956). Lahir di Bukit Tinggi, Sumatera Barat pada tahun 1869, ia pergi ke Mekkah pada tahun 1881 untuk melanjutkan pendidikan Islam. Setelah 12 tahun belajar, dia pindah ke Kairo untuk belajar Astronomi Islam di Universitas Al-Azhar. Selama periode inilah dia akrab dengan pemikiran Muhammad 'Abduh, belajar dengannya dan berkenalan dengan muridnya: Rasyid Ridha. Ketika Tahir Jalaluddin kembali ke Mekah untuk posisi mengajar, dia tetap berhubungan dengan Ridha dengan menyumbangkan artikel di edisi awal jurnal Al-Manar. Setelah Tahir Jalaluddin kembali ke Asia Tenggara pada tahun 1899, ia menetap secara permanen di Malaya pada tahun 1906. Hubungannya dengan Rashid Ridha telah memberinya otoritas keagamaan yang kemudian menyebarkan ajaran reformisme Islam di Asia Tenggara. Lebih jauh, dia menentang otoritas beberapa ulama yang termasuk dalam mazhab Syafi'i dengan mengkritik beberapa praktik masyarakat setempat yang dia yakini bertentangan dengan Al-Qur'an dan hadis. Untuk mendukung pekerjaan dan aktivismenya, Tahir Jalaluddin menerbitkan jurnal Al-Imam (1906-1908) yang meniru isi Al-Manar. Untuk jurnal ini, dia mengundang murid-muridnya yang dia ajar di Mekah untuk menjadi koresponden Al-Imam di Sumatera Barat, yaitu: Abdullah Ahmad (1878-1933), Djamil Jambek (1862-1947) dan Abdul Karim Amrullah (Haji Rasul) (18791945). Hubungan antara Tahir Jalaluddin dan ketiga muridnya ini kemungkinan besar berkontribusi pada penyebaran reformisme Islam di Sumatera Barat. Sebagaimana dikemukakan oleh Hamka (1958, 77), Tahir Jalaluddin secara rutin berkorespondensi
} 
dalam sejarah di Padang terjadi pada tahun 1919. Personilnya juga sama, yaitu Abdullah Ahmad bersama seorang pendukung Kaum Muda lainnya yaitu Syech Djamil Jambek melawan Chatib Ali. Isu perdebatan juga sama yaitu mengenai hukum qiyam ketika pembacaan Maulid Nabi dan juga topik lain seperti membaca usalli ketika niat shalat. ${ }^{8}$

Selain di kawasan Sumatra, debat terbuka lainnya yang tercatat terjadi di perhelatan kongres Al-Islam pertama pada bulan November 1922 di Cirebon. Kongres ini merupakan inisiatif Sarekat Islam (SI), sebuah organisasi Islam di masa itu yang cukup terpandang. Ide untuk mengumpulkan ormas Islam dilakukan untuk menanggapi berbagai isu di tanah air dan dunia Islam, salah satunya perubahan konstelasi kekhalifahan dan efeknya terhadap Mekah yang saat itu dibawah kekuasaan Turki Usmani. Kongres saat itu dihadiri SI sebagai tuan rumah dan beberapa ormas modernis seperti Muhammadiyah dan al-Irsyad. Sedangkan dari kelompok tradisionalis, dikarenakan belum mempunyai organisasi, diwakili oleh KH. Abdul Wahab Chasbullah (m. 1971) dan KH Asnawi Kudus (m. 1959). Ada dua topik besar yang dibahas dalam acara tersebut. Yang pertama tentang Kekhalifahan Turki Usmani dimana kongres mengirim telegram memberikan selamat kepada Mustafa Kemal. Ucapan selamat ini berhubungan dengan sultan terakhir Turki Usmani yang dianggap bersekongkol dengan pemerintahan Inggris. Yang kedua, dan termasuk paling dominan dalam pembahasan, adalah perdebatan antara kelompok modernis yang diwakili oleh ketua al-Irsyad, Ahmad Surkati dengan perwakilan kelompok tradisional. Kelompok yang terakhir menuduh kelompok pertama merencanakan revolusi dalam Islam dengan menegasikan mazhab dan menafsirkan Qur'an dan Hadis semau mereka sendiri. ${ }^{9}$ Pada akhirnya kongres yang pertama ini bersepakat bahwa

dengan ketiga muridnya ini melalui surat dan publikasi Al-Imam. Hubungan ini menginspirasi murid-murid Tahir Jalaluddin untuk menerbitkan jurnal mereka sendiri yang berjudul Al-Munir (1911-1915). Untuk lebih detail mengenai reformisme Islam di Asia Tenggara dan Indonesia silahkan baca diantaranya William Roff, The Origins of Malay Nationalism (New Haven and London: Yale University Press, 1967); Azyumardi Azra, "The Transmission of Al-Manar's Reformism to the Malay-Indonesian World: The Cases of alImam and Al-Munir," Studia Islamika 6, no. 3 (1999): 75-100; Jajat Burhanuddin, "'Islamic Knowledge, Authority, and Political Power: The "Ulama in Colonial Indonesia" (PhD Thesis, Leiden University, 2007); Hafiz Zakariya, "Islamic Reform in Malaya: The Contribution of Shaykh Tahir Jalaluddin," Intellectual Discourse 13, no. 1 (2005): 49-72.

${ }^{8}$ Kaptein, "The Berdiri Mawlid Issue among Indonesian Muslims in the Period from circa 1875 to $1930 . "$

9 Martin van Bruinessen, "Muslims of the Dutch East Indies and the Caliphate Question," Studia Islamika 2, no. 3 (1995): 127. 
kedua kelompok saling menghormati bahwa baik ijtihad maupun taqlid mazhab adalah dua kepercayaan masyarakat Muslim Indonesia. Namun begitu, sebagaimana di catat oleh Deliar Noer, bahwa kongres tersebut gagal menyatukan kelompok modernis dan tradisional. ${ }^{10}$

Tiga fakta diatas, merupakan beberapa contoh bagaimana kerasnya perdebatan antara kelompok modernis dan tradisional. Perdebatan yang terus berulang seputar perbedaan pemahaman keagamaan yang mereka punya. Perbedaan ini kemudian memunculkan kekecewaan yang sangat bagi kalangan tradisional hingga membuat mereka memutuskan mendirikan Nahdlatul Ulama (NU).

Ide tentang pendirian organisasi tersebut berawal dari kalahnya Syarif Husain, penguasa Hijaz dari Ibn Saud dan penghapusan kekhalifahan Turki Usmani pada tahun 1924. Menanggapi perkembangan tersebut, umat Islam di Hindia Belanda membentuk Komite Khilafah pada Kongres Luar Biasa Al-Islam pada tahun 1924. Pembentukan komite tersebut sebagai respon untuk memenuhi undangan ulama Al-Azhar pada konferensi khilafah internasional. Ketika Al-Azhar menunda kongres dan Ibn Saud ingin mengorganisir Kongres Umat Islam di Mekah, ada kebimbangan diantara umat Islam di Hindia Belanda untuk memilih diantara dua kongres tersebut. Friksi antara umat Islam muncul kembali, terutama ketika kelompok modernis cukup antusias dengan berita bahwa Ibnu Saud berkuasa di Hijaz. Kelompok tradisional mengajukan proposal agar mengirim surat ke Ibnu Saud supaya menghormati kebebasan bermazhab di Mekah. Sebuah usulan yang tidak digubris oleh kalangan Modernis. Atas dasar ini, kelompok tradisional membentuk kepanitiaan tersendiri dengan nama Komite Hijaz yang kemudian berkumpul dan diresmikan di Surabaya pada bulan Januari 1926. ${ }^{11}$ Pada momen inilah diresmikan sebuah organisasi sebagai payung besar kelompok tradisional dalam satu wadah bernama Nahdlatul Ulama.

Perpecahan dan terbentuknya dua komite terpisah (khilafah dan hijaz), menandai pisahnya dua kubu modernis dan tradisional dalam satu usaha mempersatukan umat Islam dalam satu plaftorm Kongres Umat Islam. Pada kongres Al-Islam berikutnya, edisi ke lima sejak dilaksanakan pada tahun 1922, NU memutuskan untuk tidak hadir. Ketidakhadiran NU tentu dengan mudah bisa dianalisa yaitu karena ketidaksetujuan NU terhadap komite khilafah dan dukungan kelompok modernis pada Ibn Saud. Namun ketidaksertaan NU pada

${ }^{10}$ Noer, Modernist Muslim Movements in Indonesia, 227-28.

${ }^{11}$ Bruinessen, "Muslims of the Dutch East Indies and the Caliphate Question." 
kongres Al-Islam hanya sementara. Pada kongres berikutnya, NU tetap ikut. Setelah itu kongres Al-Islam pun terhenti sejak 1928 sampai 1930.

Secara umum bisa dikatakan persatuan Islam di 3 dekade awal abad 20 mengalami rintangan yang cukup terjal. Dua dekade awal ini bisa dikatakan tidak ada komunikasi yang baik. Alih-alih bersatu, yang terjadi adalah perdebatan tanpa ujung mengenai pemahaman keagamaan dari kelompok modernis dan tradisional. Di dekade ke tiga, ada titik terang berkaitan dengan persatuan Islam karena konstelasi global terutama isu khilafah. Ormas Islam pun bersatu dalam satu plaftorm kongres Al-Islam. Namun begitu, riak tetap ada terutama ketika Raja Saud menguasai Hijaz dan kelompok modernis membuat komite khilafah. Karena kuatir ritual tradisional akan diberangus, kelompok tradisional membuat kepanitiaan sendiri bernama komite hijaz yang pada akhirnya menjelma menjadi organisasi Nahdlatul Ulama.

\section{MIAI dan Terjalnya Persatuan Islam}

Singkatnya, komunikasi antar ormas Islam terbangun lagi pasca kekecewaan kelompok tradisional dan kembali mereka berpartisipasi dalam kongres Al-Islam. Meski begitu, kongres ini sempat terhenti selama dua periode. Yang pertama 19281930, dan yang kedua periode tahun 1933-1937. Tidak jelas mengapa tahun-tahun ini berhenti. Kemungkinan karena kesibukan ormas masing-masing dan tidak ada isu utama yang menjadikan berbagai ormas ini bersatu. Selain itu, diantara alasan kevakuman kongres Al-Islam adalah terus meruncingnya perdebatan antara kelompok modernis dan tradisionalis. Semisal perdebatan antara Persis yang diwakili Ahmad Hassan dan NU yang diwakili oleh K. Masduqi pada tahun 1936. Pada saat itu, kedua kelompok tersebut memperdebatkan masalah ijtihad, taqlid, niat sholat dan jumlah rakaat dalam shalat tarawih. ${ }^{12}$

Namun begitu, sejak akhir dekade 1920an, mulai ada beberapa kejadian, utamanya kebijakan Belanda, yang menjadikan beberapa tokoh ormas memikirkan untuk bersatu. Ini semisal yang diceritakan oleh Hamka tentang Ayahnya, Abdul Karim Amrullah (Haji Rasul) yang mulai mengurangi kritiknya terhadap terhadap ritual kaum tua, mulai dari bacaan usalli, tahlilan dan lain sebagainya. Yang membuat Haji Rasul mengendurkan kritiknya, adalah karena adanya perasaan bahwa ada masalah besar yang harus dihadapi, sehingga perbedaan furu', harus dikesampingkan. Haji Rasul bahkan menegur keras jika ada ulama muda

${ }^{12}$ Mizan Sya'roni, "The Majlisul Islamil Ala Indonesia (MIAI): Its Socio-Religious and Political Activities (1937-1943).” (McGill University, 1998), 49. 


\section{Muhammad As'ad}

mengkritik keras kaum tua. Adanya beberapa fenomena ini, dengan sendirinya membuat perdebatan antara kaum tua-kaum muda di Sumatra Barat hilang. ${ }^{13}$ Salah satu dari kebijakan Belanda yang dicermati umat Islam pada masa itu adalah Wilde Scholen Ordonantie (Peraturan Guru Liar) pada tahun 1932/1933. Aturan ini sebenarnya sudah mulai ada di awal tahun 1920an, akan tetapi mulai diimplentasikan pada tahun 1930an. Dalam aturan ini, guru agama Islam tidak dibolehkan mengajar kecuali dapat izin Pemerintah Belanda. Ini tentu saja menjadi ancaman bagi ormas Islam. Sehingga cara untuk melawan kebijakan ini adalah dengan bersatunya umat Islam. Dan benar adanya, setelah peratuan ini muncul (sebagaimana diceritakan oleh Hamka di Sumatra Barat), kaum tua dan kaum muda mulai bersatu dan bahu membahu menolak aturan ini. ${ }^{14}$

Kebijakan ini diperparah dengan keluarnya Huwelijksordonnantie atau Rancangan Ordonansi Perkawinan Bercatat pada 1937 yang memaksa laki-laki untuk menerapkan pernikahan monogami yang pada akhirnya melarang praktek poligami. Ini kemudian membuat beberapa ormas Islam merasa harus ada upaya yang serius untuk melawan kebijakan tersebut. Karena kongres Al-Islam vakum sejak tahun 1933, munculnya kebijakan wajib monogami itu membuat ormas Islam merasa perlu untuk menghidupkan ukhuwah Islamiyah karena kebijakan pemerintah Hindia Belanda. Maka pada bulan September 1937 dibentuklah organisasi Madjelis Islam A'la Indonesia (MIAI) yang salah satu tugasnya untuk sebagai panitia persiapan kongres Al-Islam berikutnya.

Ada empat figur utama dibalik pendirian MIAI. Yang pertama adalah KH. Mas Mansur dari Muhammadiyah, Wondoamiseno dari Partai Syarikat Islam dan dua orang dari Nahdlatul Ulama (KH. Wahab Hasbullah \& KH. Muhammad Dahlan). ${ }^{15}$

${ }^{13}$ Hamka, Ajahku: Riwajat Hidup Dr. H. Abd. Karim Amrullah Dan Perdjuangan Kaum Agama Di Sumatera (Jakarta: Widjaya, 1958), 172-75.

${ }^{14}$ Hamka, Ajahku: Riwajat Hidup, 174

15 Harry J. Benda, The Crescent and the Rising Sun: Indonesia Islam under the Japanese Occupation, 1942-1945 (The Hague and Bandung: W. van Hoeve, 1958), 67; Greg Fealy, "Wahab Chasbullah, Tradisionalisme Dan Perkembangan Politik NU," in Tradisionalisme Radikal; Persinggungan Nahdlatul Ulama-Negara, ed. Greg Fealy, Greg and Barton (Yogyakarta: LKIS, 1997), 32. 


\section{Struktur Badan Sekretariat MIAI (1937-1940}

$\begin{array}{ll}\text { Penasehat } & : \text { KH. Muhammad Dahlan } \\ \text { Ketua } & : \text { Wondoamiseno } \\ \text { Bendahara } & : \text { H. Faqih Usman } \\ \text { Anggota } & : \text { | } 1 \text {. KH. Abdoel Wahab } \\ & \text { 2. S. Oemar Hoobeis } \\ & \text { 3. Sastradiwirja } \\ & \text { 4. Abdoelkadir Bahalwan }\end{array}$

Namun begitu, meskipun unsur NU adalah satu satu inisiator munculnya MIAI, ketika organisasi ini berdiri secara resmi pada tahun 1937, keterlibatan KH. Wahab hanya atas nama pribadi, bukan atas nama organisasi. Ketika MIAI berdiri tahun 1937, anggota resmi MIAI hanya berjumlah tujuh ormas. Mereka adalah:

1. Partai Sarekat Islam Indonesia (PSII).

2. Muhammadiyah

3. Al-Islam,

4. Persatuan Umat Islam.

5. Al-Irsyad

6. HidayatuI Islamiyah Banyuwangi

7. Al-Khairiyah of Surabaya. ${ }^{16}$

NU baru bergabung secara resmi dengan MIAI pada tahun 1940. Tidak diketahui dengan pasti mengapa NU baru resmi bergabung dengan MIAI 3 tahun setelah organisasi tersebut berdiri. Kemungkinan besar alasannya adalah faktor perbedaan pandangan beberapa ormas Islam yang menjadi kendala. Indikasi ini bisa terlihat pada kongres pertama MIAI pada tahun 1938, dimana utusan NU berdebat dengan PSII. Pada saat itu, NU keberatan pada sikap PSII yang ingin mendapatkan kredit dan menjadi pemimpin umat Islam terutama karena inisiatif mereka membuat kongres Al-Islam pada tahun 1920an. Menurut NU, MIAI adalah usaha baru ukhuwah Islamiyah yang berbeda dengan inisiatif pada tahun 1920an. Keinginan PSII yang ingin menjadi pemimpin tidak dapat diterima karena menganggap itu adalah kepentingan politik PSII. Karena perbedaan

${ }^{16}$ Sya'roni, "The Majlisul Islamil Ala Indonesia (MIAI)." 
tersebut, NU keluar dari kongres. ${ }^{17}$ Namun begitu, beberapa perbedaan ini bisa dikesampingkan karena adanya cita-cita bersama yaitu keinginan untuk melawan kebijakan Belanda yang mendiskreditkan umat Islam. Sehingga meskipun ada perbedaan pandangan, NU pada akhirnya bergabung dengan MIAI pada tahun 1940. ${ }^{18}$

\author{
Dewan MIAI (1940-1942) \\ Ketua : H. A. Wahid Hasyim \\ Wakil : Wondoamiseno \\ Anggota: 1. S. Oemar Hobeis \\ 2. S K. H. M. Mas Mansur \\ 3. Sastradiwirja \\ 4. Dr. Soekiman
}

Sekretariat MIAI

Ketua

: H. Faqih Usman

Sekretaris

Bendahara

: Abdoelkadir Bahalwan

: Sastradiwirja

Yang juga dianggap sebagai inspirator MIAI adalah KH. Hasyim Asy'ari, meskipun secara fisik tidak terlibat dalam pendiriannya. Yang dimaksud dengan inspirator disini adalah keinginan Hadratussyaikh untuk menyatukan umat Islam. Dalam kongres NU ke 15 di Banjarmasin pada tahun 1936, Hadratussyaikh menginginkan ulama untuk tidak fanatik kepada satu mazhab yang mengakibatkan perpecahan umat. Disamping itu, secara implisit, beliau juga meminta kaum modernis jika tidak sepakat, maka yang harus dilakukan adalah mengingatkan dengan cara yang santun. Dan jika yang dikritik tidak menerima, maka jangan sampai bermusuhan dan menghancurkan keinginan untuk mempersatukan umat Islam. ${ }^{19}$

${ }^{17}$ Ahmad Syafii Maarif, Islam Dan Politik: Teori Belah Bambu, Masa Demokrasi Terpimpin, 1959-1965 (Gema Insani, 1996), 18.

18 Anggota MIAI pada tahun 1941: 1. Partai Sarekat Islam Indonesia. 2. Muhammadiyah. 3. Persatuan Islam. 4. Nahdlatul Ulama. 5. AI- lrsyad. 6. Jong Islamieten Bond. 7. Partai Islam Indonesia. 8. AI-Ittihadul Islamiyah Sukabumi. 9. AI-Islam Solo. 10. Persatuan Arab Indonesia. II. Persatuan Ulama Seluruh Aceh (PUSA). 12. Musyawaratut Thalibin Kandangan, Sulawesi. 13. Persatuan Ulama Islam MajaIengka. Lihat Sya'roni, "The Majlisul Islamil Ala Indonesia (MIAI)," 57.

${ }^{19}$ Sya'roni, "The Majlisul Islamil Ala Indonesia (MIAI)," 57. 
Sebagai murid Hadratussyaikh, tentunya KH. Wahab Hasbullah paham tentang keinginan sang guru. Keterlibatan beliau dalam pendirian MIAI bisa dikatakan terinspirasi oleh Hadratussyaikh yang menginginkan persatuan Islam dengan menegasikan perbedaan furu' diantara ormas Islam. Dari sinilah kemudian bisa diketahui, mengapa $\mathrm{KH}$. Wahab Hasbullah terlibat aktif dalam proses pendirian MIAI. ${ }^{20}$

\section{Jepang Mengkooptasi Islam}

Sebelum mendiskusikan MIAI dan Masyumi zaman Jepang, perlu dibahas sebelumnya tentang perbedaaan kebijakan penjajah Belanda dan Jepang terkait Islam. Perbedaan antara keduanya yang menyebabkan mengapa Masyumi muncul pada zaman penjajah Jepang, bukan pada zaman penjajah Belanda.

Secara umum bisa dikatakan bahwa kebijakan Belanda terkait Islam adalah dalam bidang agama pemerintah kolonial bersikap netral dan memberikan kebebasan untuk beribadah, akan tetapi terkait politik yang mengatasnamakan Islam, dibatasi atau bahkan ditekan. Kebijakan seperti ini didesain oleh Professor Studi Islam dari Leiden, Snouck Hurgronje. ${ }^{21}$ Namun begitu, dalam tataran pelaksanaan, Belanda seringkali melakukan intervensi dalam kaitan hukum Islam. Contohnya pada masalah aturan tentang guru agama dan juga tentang pelarangan terhadap poligami.

Jepang sebetulnya berprinsip sama dengan Belanda, akan tetapi pada masa awal sebelum menjajah Indonesia, Jepang berubah haluan karena merasa Islam punya potensi untuk digunakan sebagai alat untuk melawan pasukan sekutu. Pikiran ini muncul ketika Jepang menjajah Cina bagian utara dan masuk wilayah Xinjiang yang sebagian besar beragama Islam. Ini yang membuat Jepang mengirim beberapa utusannya belajar Islam termasuk ke Al-Azhar. Ini juga alasan mengapa pada tahun 1937-1939 dicatat sebagai masa dimana Jepang membuat banyak usaha untuk mengenal Islam, termasuk dengan membuat banyak lembaga dan pameran-pameran. Akan tetapi, ketika Jepang masuk ke Indonesia pada bulan 1 Maret 1942, pengetahuan mereka tentang Islam masih sangat minim. Yang mereka ketahui hanya Islam punya potensi anti-barat yang sangat kuat. Jepang tidak paham besarnya pengaruh NU di masyarakat. Mereka hanya menganggap

\footnotetext{
${ }^{20}$ Choirul Anam, Pertumbuhan Dan Perkembangan NU (Solo: Jatayu, 1985).

21 Harry J. Benda, "Christiaan Snouck Hurgronje and the Foundations of Dutch Islamic Policy in Indonesia," The Journal of Modern History 30, no. 4 (1958): 338-347; Yasuko Kobayashi, "Islam during the Japanese Occupation," in The Encyclopaedia of Indonesia in the Pacific War, Leiden, Boston: Brill, ed. Peter Post, 2010, 300-11.
} 
NU tidak jauh berbeda pengaruhnya dari Muhammadiyah. ${ }^{22}$ Ketidakpahaman ini pula yang menyebabkan Jepang menahan Hadratussyaikh selama tiga bulan karena menolak kewajiban melakukan saikeirei (membungkuk menghadap matahari). Kebijakan Jepang ini menimbulkan banyak kecaman tidak hanya dari pemimpin Indonesia, tetapi juga oleh tokoh Jepang yang ahli Islam. ${ }^{23}$

Kurangnya pengetahuan tentang peta politik ormas Islam Indonesia juga yang membuat Jepang memilih untuk menghidupkan MIAI pada bulan September 1942. Selain itu, tokoh MIAI dari PSII, Wondoamiseno, memberikan informasi bahwa PSII dan Muhammadiyah adalah organisasi Islam yang paling bagus serta merekomendasikan untuk tidak memilih NU. Karena menurut dia, "NU terdiri dari orang-orang yang buta huruf, fanatik dan tidak berpendidikan". ${ }^{24}$ Atas dasar ini, Jepang memilih menghidupkan kembali MIAI dan memindahkan markas MIAI dari Surabaya ke Batavia.

$\begin{array}{ll}\text { Sekretariat } & \text { MIAI (1942-1943) } \\ \text { Ketua } & \text { : Wondoamiseno } \\ \text { Sekretaris } & \text { : Harsono Tjokroaminoto } \\ \text { Bendahara } & \text { : R. H. O. Djoenadi } \\ \text { Anggota } & \text { : 1. Mr. Kasman Singodimedjo } \\ & \text { 2. Farid Ma'ruf } \\ & \text { 3. Mahfud Siddiq } \\ & \text { 4. K. H. A. Wahid Hasjim } \\ & \text { 5. Ki Bagus Hadikusumo } \\ & \text { 6. Dr. Sukiman } \\ & \text { 7. Raden Adnan }\end{array}$

Dewan Penasehat

Ketua

: K. H. Mas Mansur

Anggota

: 1. KH. Hasjim Asfari

2. Dr. H. A. Karim Amrullah (Haji Rasul)

3. Sayed Ali al-Habsji

4. Sjekh Ahmad Sorkati

5. Ki Bagus Hadikusumo

6. Inada Ono

7. Abdul Hasan|

\footnotetext{
${ }^{22}$ Kobayashi, "Islam during the Japanese Occupation," 304.

${ }^{23}$ Kobayashi Yasuko, "Kyai and Japanese Military," Studia Islamika 4, no. 3 (1997): 77.

${ }^{24}$ Yasuko, 81.
} 
Pasca aktifnya MIAI, Jepang pelan-pelan memahami bahwa para kyai mempunyai peran besar diantara masyarakat. Namun begitu, meskipun pada akhirnya Jepang mempercayai kyai, bukan berarti tanpa kepentingan politik. Semuanya bertujuan untuk memperalat kelompok Islam untuk tujuan utama mereka. Yaitu memengaruhi masyarakat bawah agar bisa dimobilisasi untuk kepentingan melawan sekutu di Perang Dunia ke $2 .^{25}$ Karena tujuan ini pula, mulai bulan Desember 1942 hingga Februari 1943, ketua Shumubu pertama, Kolonel Horie membuat serangkaian pertemuan dengan para kyai dari berbagai daerah. Mereka dijamu dengan bagus dan pendapat mereka didengar pemerintah kolonial Jepang. Dari beberapa pertemuan ini, Jepang secara resmi berpendapat bahwa kyai bukan saja tokoh agama, tetapi juga tokoh politik. Maka mulai bulan Juli 1943, Jepang melaksanakan program pelatihan ribuan kyai yang mana sebagian besar dari mereka adalah anggota NU. Salah satu tujuan dari pelatihan ini adalah agar para kyai mendukung Jepang serta mendeklarasikan perang melawan sekutu sebagai jihad fi sabilillah. ${ }^{26}$ Pada akhirnya, kebijakan ini secara umum bisa dikatakan berbeda dengan Belanda yang berusaha netral dalam urusan agama. Sedangkan Jepang, punya kecenderungan memihak umat Islam untuk tujuan politik tertentu.

Menurut Kobayashi Yasuko, ada satu tokoh Muslim Jepang dibalik perubahan kebijakan penjajah Nippon di Jawa. Yang awalnya membekukan seluruh ormas Islam, menjadi memberikan ruang kepada ormas Islam pilihan. ${ }^{27}$ Dia adalah Abdul Hamid Ono yang menikah dengan orang Jawa dan tinggal beberapa lama di Surabaya. Ono pula yang menyarankan Jepang untuk memberi perhatian lebih kepada NU dan kyai. Menurut Ono, kyai mempunyai peran dan pengaruh penting di masyarakat. Ono memberikan 5 rekomendasi kepada Jepang untuk kebijakan terkait Islam:

1. Biarkan masyarakat Jawa bebas melaksanakan agama Islam.

2. Untuk kalangan konservatif (NU), berikan kepercayaan secara penuh kepada kyai karena popularitas mereka, dan jadikan mereka boneka.

3. Untuk kalangan progresif (Muhammadiyah), wajibkan program bahasa Jepang di sekolah Muhammadiyah).

25 Muhammed Abdul Aziz, “Japan's Colonialism and Indonesia. The Hague, M. Nijhoff, 1955” (PhD Thesis, Leiden University, 1973), 200.

${ }^{26}$ Aziz, 2002.

27 Peter Post, The Encyclopedia of Indonesia in the Pacific War: In Cooperation with the Netherlands Institute for War Documentation (Brill, 2009), 542. 
4. Lakukan Jepangisasi melalui disiplin militer.

5. Perhatikan hal-hal yang menimbulkan kebencian terhadap orang kafir (asing). ${ }^{28}$

Ketika mulai percaya kepada kyai, Jepang merasa sudah saatnya membubarkan MIAI. Terlebih lagi Jepang merasa MIAI menjadi ancaman. Salah satu alasannya adalah pada bulan Mei 1943, MIAI membuat Baitul Mal tidak hanya di Jakarta tetapi di 34 Kabupaten di pulau Jawa. Apalagi dalam pernyataannya, ketua MIAI, Wondoamiseno, mengatakan bahwa salah satu tujuan pendirian Baitul Mal adalah untuk membantu peperangan demi kemenangan Jepang. ${ }^{29}$ Meskipun disebutkan untuk kemenangan Jepang, sepertinya Jepang curiga gelagat pengumpulan dana ini dan merasa usaha tersebut sebagai tindakan yang tidak dapat dibiarkan. Dengan visi MIAI yang berdiri tahun 1937 sebagai upaya melawan penjajah Belanda, Jepang merasa MIAI punya potensi merongrong Jepang termasuk upaya mereka untuk mengkooptasi para kyai melalui program pelatihan yang dijalankan pemerintah Jepang. Sehingga untuk memutus rantai pengaruh MIAI di daerah, maka diputuskan organisasi ini dibubarkan pada 24 Oktober 1943.

\title{
Struktur Masyumi
}

\section{Ketua Besar : KH. Hasyim Asy'ari \\ Ketua Muda I : KH. Mas Mansur \\ Ketua Muda II : KH. Wahid Hasyim}

\author{
Anggota: \\ 1. KH. Nachrowi \\ 2. H. Hasjim \\ 3. K. H. Moechtar \\ 4. Zainoel Arifin \\ 5. KH. Sodri \\ 6. H. Farid Ma'roef \\ 7. H. Abdoel Moektil \\ 8. T. Kartosoedharmo \\ Penasehat Tertinggi \\ 1. KH. Abdulwahab \\ 2. Hadikoesomo
}

${ }^{28}$ Yasuko, "Kyai and Japanese Military," 77.

${ }^{29}$ Wondoamiseno, "Baitul Mal," Soeara Madjlis Islam A'lam Indonesia, July 1, 1943. 
Setelah MIAI dibubarkan, Jepang mendirikan Masyumi pada tanggal 22 November 1943. Berbeda dengan MIAI yang keanggotaannya bebas diputuskan oleh berbagai ormas Islam yang berdiri di Indonesia, keanggotaan Masyumi diatur oleh Jepang khususnya oleh Shumubu, sebuah lembaga yang menjadi cikal bakal Kementerian Agama. Pada saat berdiri pada bulan November, keanggotaan ormas Islam dalam Masyumi hanya dua: Muhammadiyah dan Nahdlatul Ulama. Hal ini dikarenakan dua ormas ini yang diberi legalitas oleh Jepang pada bulan September 1943. Selain itu, jika ada kyai atau ulama ingin menjadi anggota Masyumi secara pribadi, mereka juga harus mendapatkan rekomendasi Shumubu. Jadi bisa dikatakan, berbeda dengan MIAI, Masyumi berada dalam kontrol sepenuhnya pemerintahan Jepang. ${ }^{30}$ Untuk struktur kepengurusan, Hadratussyaikh dipilih sebagai ketua besar. Mendampingi Hadratussyaikh, adalah ketua muda I yang diisi oleh KH. Mas Mansur dan ketua muda II oleh KH. Wahid Hasyim. ${ }^{31}$

Dari struktur keseluruhan, bisa dilihat bahwa pengurus harian Masyumi hanya diisi oleh personil ormas Muhammadiyah dan NU. Diluar keduanya, sepertinya Jepang tidak memberikan ruang. Alasan mengapa kedua ormas ini yang diberi jatah posisi pengurus? Sepertinya Jepang belajar bahwa setelah hampir 16 bulan menjajah Indonesia, mereka mengetahui bagaimana besar peran kedua ormas ini di mata masyarakat, khususnya lagi Nahdlatul Ulama. Ini pula alasan mengapa posisi ketua besar diberikan kepada Hadratussyaikh. Padahal beliau sebelumnya pernah dipenjara selama 3 bulan di tahun 1942. Jepang berharap ketokohan Hadratussyaikh di NU bisa membantu mereka memobilisasi rakyat utamanya berkaitan dengan kampanye mereka untuk menghadapi sekutu pada Perang Dunia ke 2. Keputusan Jepang ini sepertinya menyesuaikan dengan rekomendasi Abdul Hamid Ono yang saya tulis di halaman sebelumnya. Dimana dalam rekomendasinya, Ono mengatakan agar Jepang memberikan kepercayaan secara penuh kepada kyai karena popularitas mereka, dan jadikan mereka sebagai boneka. $^{32}$

Keinginan untuk menggunakan pengaruh kyai semakin diperbesar dengan pendirian cabang-cabang Masyumi di berbagai daerah. Dan sebagaimana di pusat di mana Masyumi pusat didukung oleh Shumubu tingkat pusat, di daerah pun begitu. Masyumi tingkat daerah didukung oleh lembaga pemerintah, dimana Jepang mendirikan Kantor Urusan Agama tingkat daerah (Shumuka) yang salah

${ }^{30}$ Benda, The Crescent and the Rising Sun: Indonesia Islam under the Japanese Occupation, 1942-1945, 185.

${ }^{31}$ Soeara Moeslimin Indonesia, December 1, 1943, 18.

${ }^{32}$ Yasuko, "Kyai and Japanese Military," 77. 
satu tugasnya mendukung kegiatan Masyumi. Ini sepertinya yang menjadi alasan mengapa posisi ketua Shumubu diserahkan dari Kolonel Horie kepada Husain Djayadiningrat, murid Snouck Hurgronje yang juga orang Indonesia pertama yang mendapat gelar doktor dari Universitas Leiden. Tujuannya untuk mendekatkan komunikasi Masyumi kepada Shumubu, serta juga memudahkan Shumubu mengorganisir umat Islam.

Salah salah program Shumubu untuk alasan yang terakhir ini adalah memberikan pelatihan-pelatihan militer kepada kalangan kyai di pulau Jawa. ${ }^{33}$ Meskipun pada akhirnya, setengah tahun setelah Shumubu dijabat oleh Husain Djayadiningrat, pada bulan Agustus 1944 posisi ini diberikan kepada Hadratussyaikh. ${ }^{34}$ Digantinya Husain Djayadingingrat, karena dia dianggap tidak bisa meredam pemberontakan kyai NU di Singaparna: Kyai Zainal Mustafa. Ketika posisi ketua Shumubu diberikan kepada Hadratusssayaikh, Jepang mengharapkan agar Hadratussyaikh bisa mengendalikan umat Islam di tataran bawah. Selain itu, dengan diberikannya posisi Masyumi dan Shumubu sekaligus kepada Hadratussyaikh, Jepang juga menginginkan hubungan antara pemerintahan militer Jepang yang ada di struktur Shumubu dan pemimpin umat Islam yang ada di Masyumi bisa terjalin lebih erat. ${ }^{35}$

Dari fakta diatas, kita bisa melihat bahwa diberikannya posisi Ketua Besar Masyumi dan Ketua Shumubu kepada Hadratussyaikh adalah karena faktor politik. Terutama terkait kebijakan Jepang ketika menjajah Indonesia, yaitu untuk "menaklukkan hati" kelompok Islam. Caranya dengan mendapatkan simpati dan dukungan umat Islam pada kampanye perang yang dilakukan Jepang. Ini pula yang mendasari Jepang memilih NU dan Hadratussyaikh yang dipandang membawahi jutaan umat Islam di Indonesia. Dengan pilihan ini, Jepang menganggap pengangkatan beliau bisa mengontrol dan memengaruhi umat Islam Indonesia. Terkait kontrol, Jepang ingin tidak ada lagi usaha pemberontakan umat Islam kepada pemerintah kolonial, sebagaimana kasus di Singaparna. Dan untuk pengaruh, Jepang ingin agar umat Islam bisa membantu Jepang atas nama jihad untuk membantu perang mereka melawan sekutu. Itu pula yang mendasari Jepang melatih umat Islam dalam satu korps pasukan Hizbullah dan Sabilillah.

Namun begitu, meskipun kebijakan Jepang terkait Islam dan pilihan untuk mengangkat Hadratussyaikh sebagai ketua Masyumi dan Shumubu terlihat

${ }^{33}$ Benda, The Crescent and the Rising Sun: Indonesia Islam under the Japanese Occupation, 1942-1945, 193.

${ }^{34}$ Soeara Moeslimin Indonesia, 15 Agustus 1944, 20.

${ }^{35}$ Aziz, "Japan’s Colonialism nd Indonesia. The Hague, M. Nijhoff, 1955," 207. 
negatif, keputusan politik ini mempunyai pengaruh yang sangat kuat terhadap Indonesia sampai saat ini. Yaitu berhasilnya kelompok Islam menjadi salah satu elemen penting di politik Indonesia. Jika masa penjajahan Belanda posisi penting di wilayah politik hanya diberikan kepada priyayi, keputusan Jepang mendirikan MIAI, Masyumi dan Shumubu membuat kelompok Islam mempunyai daya tawar politik yang cukup kuat. Sejak Jepang menjajah, kelompok Islam punya perwakilan di lembaga tingkat nasional. Dan jejaknya diteruskan oleh Partai Masyumi yang berdiri tahun 1945 ataupun Partai NU yang keluar dari Masyumi pada 1952. Efek kebijakan ini bisa dilihat dari partai-partai Islam saat ini, dimana semuanya tidak bisa dilepaskan baik secara ideologis maupun genealogis dari Partai Masyumi dan Partai NU. Lebih khusus untuk tokoh NU, kebijakan Jepang membuat banyak figur NU yang menjadi tokoh nasional. Paling tidak posisi Menteri Agama yang selalu dipandang menjadi “jatah" NU dari zaman pemerintah Orde Lama, sampai saat ini.

\section{Kesimpulan}

Dari artikel ini kita bisa melihat bahwa umat Islam Indonesia sejak awal abad 20 selalu diisi dengan perdebatan furuiyah. Terutama sejak masuknya pemikiran modernisme Islam di awal abad 20. Perdebatan furuiyah ini selalu menjadi ganjalan ketika ada ide persatuan umat Islam dan tentunya berpengaruh kepada perlawanan umat Islam terhadap kebijakan pemerintah kolonial.

Umat Islam Indonesia bisa bersatu salah satunya karena faktor eksternal. Seperti disepakatinya pendirian MIAI oleh pemimpin ormas Islam pada tahun 1937 karena ada dua Undang-Undang pemerintah kolonial Belanda yang dianggap merugikan umat Islam. Berbeda dengan Belanda yang dalam kebijakan politik merugikan umat Islam, Jepang lebih memihak kelompok Islam karena mereka punya kepentingan terkait kekalahan Jepang di Perang Pasifik. Jepang menganggap jika umat Islam bisa dikontrol, melalui pengaruh para kyai, kampanye untuk mobilisasi massa di perang Pasifik bisa terlaksana.

Dipilihnya Hadratussyaikh sebagai ketua Masyumi dan Shumubu adalah karena faktor politik tersebut. Harapannya ketika Hadratussyaikh menjadi ketua dari dua lembaga penting diatas, umat Islam lebih mudah terkontrol dan tentunya lebih mudah dimobilisasi ketika Jepang berperang melawan sekutu di Perang Dunia ke 2. Meskipun kebijakan kooptasi kelompok Islam ini terlihat negatif, akan tetapi dalam jangka panjang menguntungkan kelompok Islam. Karena pasca kebijakan ini, dan khususnya pasca kemerdekaan Indonesia pada tahun 1945, banyak tokoh dan ormas Islam bermunculan. Sesuatu yang pada zaman 


\section{Muhammad As'ad}

penjajahan Belanda susah bahkan bisa dibilang sangat mustahil karena tekanan pemerintah kolonial pada Islam Politik. Saat itu, Belanda lebih memprioritaskan kaum priyayi khususnya untuk menjadi pegawai di administrasi pemerintahan kolonial, daripada kaum santri.

Ketika kaum santri mendapat celah politik ketika Jepang mengalahkan Belanda dengan berbagai kebijakannya terutama dengan memperbolehkan MIAI untuk aktif di tahun 1942, pendirian Masyumi dan Shumubu di tahun 1943, banyak tokoh Islam, salah satunya dari Nahdlatul Ulama menjadi tokoh kunci kemerdekaan Indonesia. Karena sudah mendapat tempat di politik Indonesia sejak MIAI, Masyumi dan Shubumu berdiri.

\section{Referensi}

Adams, Charles. Islam and Modernism in Egypt: A Study of the Modern Reform Movement Inaugurated by Muhammad Abduh. New York: Oxford University Press, 1933.

Anam, Choirul. Pertumbuhan Dan Perkembangan NU. Solo: Jatayu, 1985.

Aziz, Muhammed Abdul. “Japan's Colonialism and Indonesia. The Hague, M. Nijhoff, 1955.” PhD Thesis, Leiden University, 1973.

Azra, Azyumardi. "The Transmission of Al-Manar's Reformism to the MalayIndonesian World: The Cases of al-Imam and al-Munir." Studia Islamika 6, no. 3 (1999): 75-100.

Benda, Harry J. "Christiaan Snouck Hurgronje and the Foundations of Dutch Islamic Policy in Indonesia." The Journal of Modern History 30, no. 4 (1958): 338-347.

- The Crescent and the Rising Sun: Indonesia Islam under the Japanese Occupation, 1942-1945. The Hague and Bandung: W. van Hoeve, 1958.

Bruinessen, Martin van. "Muslims of the Dutch East Indies and the Caliphate Question." Studia Islamika 2, no. 3 (1995): 115-40.

Burhanuddin, Jajat. "Islamic Knowledge, Authority, and Political Power: The 'Ulama in Colonial Indonesia." PhD Thesis, Leiden University, 2007.

Esposito, John L. The Oxford Dictionary of Islam. Oxford University Press, 2004. Hamka. Ajahku: Riwajat Hidup Dr. H. Abd. Karim Amrullah Dan Perdjuangan Kaum Agama Di Sumatera. Jakarta: Widjaya, 1958.

Hodgson, Marshall GS. The Venture of Islam, Volume 1: The Classical Age of Islam. University of Chicago press, 2009. 
Kaptein, Nico. "The Berdiri Mawlid Issue among Indonesian Muslims in the Period from circa 1875 to 1930." Bijdragen Tot de Taal, Land- En Volkenkunde 149, no. 1 (1993): 124-153.

Kobayashi, Yasuko. "Islam during the Japanese Occupation." In The Encyclopaedia of Indonesia in the Pacific War, Leiden, Boston: Brill, edited by Peter Post, 30011, 2010.

__, "Kyai and Japanese Military." Studia Islamika 4, no. 3 (1997).

Maarif, Ahmad Syafii. Islam Dan Politik: Teori Belah Bambu, Masa Demokrasi Terpimpin, 1959-1965. Gema Insani, 1996.

Noer, Deliar. Modernist Muslim Movements in Indonesia. Kuala Lumpur: Oxford University Press, 1973.

Post, Peter. The Encyclopedia of Indonesia in the Pacific War: In Cooperation with the Netherlands Institute for War Documentation. Brill, 2009.

Roff, William. The Origins of Malay Nationalism. New Haven and London: Yale University Press, 1967.

Sharabi, Hisham. Arab Intellectuals and the West: The Formative Years, 1875-1914. Baltimore and London: Johns Hopkins University Press, 1970.

Soeara Moeslimin Indonesia, December 1, 1943.

—, Agustus 1944.

Sya'roni, Mizan. "The Majlisul Islamil Ala Indonesia (MIAI): Its Socio-Religious and Political Activities (1937-1943)." McGill University, 1998.

Van Bruinessen, Martin. "Trmaditions for the Future: The Reconstruction of Traditionalist Discourse within NU." In Nahdlatul Ulama, Traditional Islam and Modernity in Indonesia, edited by Greg Barton and Greg Fealy, 163-189. Clayton: Monash Asia Institute, 1996.

Wondoamiseno. "Baitul Mal." Soeara Madjlis Islam A'lam Indonesia, July 1, 1943.

Zakariya, Hafiz. "Islamic Reform in Malaya: The Contribution of Shaykh Tahir Jalaluddin." Intellectual Discourse 13, no. 1 (2005): 49-72. 